\title{
Height versus Weight which Cassel Parameter Determine Pulmonary Functions Fitness among the Algerians Soccer Players
}

\section{Zerf Mohammed*, Houar Abelatif, Mime Mokhtar and Bengoua Ali}

Physical Education Institute Laboratory OPAPS, University of Mostaganem, Mostaganem, Algeria

\begin{abstract}
Our study evaluated relationships between two surrogate measured vital capacity and aerobic capacity of predict Anthropometric Characteristics Determine the Cardiorespiratory Fitness among Soccer Players. Whereas our background confirms that weight-for-height as a relationship, were not considered in the kinematics analysis during the match. For the propose a total of 163 male soccer players under 17 years from the Algerian football championship participated in the present study. There $\mathrm{VO}_{2}$ max were estimated based on the formula Test Cooper $\left(\mathrm{VO}_{2} \max =22.351\right.$ $\mathrm{d}(\mathrm{km})-11.288(\mathrm{ml} / \mathrm{min} / \mathrm{kg}))$ where Vital capacity was calculating based on formula (vital capacity $(\mathrm{ml})=(27.63-0.112$ $\times$ age $) \times$ height $(\mathrm{cm})$ ). Based on the statistical applied. Our results confirm: 1) There is a strong positive relationship between maximal aerobic capacity and the Vital capacity, 2) Height is the most predictor of Vital capacity, 3) Height is the most predictor of the maximal aerobic capacity in the case of our sample.
\end{abstract}

Keywords: Height; Weight; Maximal aerobic capacity; Vital capacity;

Pulmonary fitness

\section{Introduction}

In sports, performance profile of player/team is related to both biological and environmental factors [1,2]. Whereas despite the most physiological data on elite soccer players originate from Western Europe and North America [3]. Where they base their calculated on the methods kinematic analysis during match play including the distance covered by players in a match to calculate the index of physiological demands presented by the total distance covered in a game $[4,5]$. From the moment that the distance is the most kinematic parameter used to determine an estimate maximal aerobic capacity [6]. The main objective of this study was to analyse the correlation between the Height Versus Weight as Parameter to esteem in one hand, the Vital capacity which is the maximum amount of air a person can expel from the lungs after a maximum inhalation where we choose the formula of Seikel et al. [1] in other hand, we chose the maximal aerobic capacity which is the maximum rate of Oxygen consumption as measured, where the maximal Oxygen uptake has not only been used as an index of physical activity, but provides valuable information about Oxygen transportation in our case we based on the formula of Test Cooper [7-10]. From the proof that the vital capacity is measure to compare and control the improvement on $\mathrm{VO}_{2}$ max case sports studies, and the way to determine the severity of respiratory muscle involvement in neuromuscular disease case the medical studies $[11,12]$. Whereas the $\mathrm{VO}_{2}$ max is the maximum rate at which an individual can take up and utilize Oxygen while breathing air at sea level [13]. Our interest is low on formulas which estimate the vital capacity based on age, sex and height [14]. Furthermore, the $\mathrm{VO}_{2}$ max formula chosen in the current study it is based on the esteem of time and distance [15]. From the considering, our interest in this study are to tested the correlation between the two formulas to predict the anthropometric Parameter witch improve the accuracy of the respiratory functions among soccer players. For this reason, a total of 163 male soccer players under 17 years from the Algerian football championship participated in the present study. There $\mathrm{VO}_{2}$ max were estimated based on the formula Test Cooper [16] $\left(\mathrm{VO}_{2}\right.$ $\max =22,351 \mathrm{~d}(\mathrm{~km})-11.288(\mathrm{ml} / \mathrm{min} / \mathrm{kg}))$, where Vital capacity was calculating based on formula (vital capacity $(\mathrm{ml})=(27.63-0.112 \times$ age $)$ $\times$ height $(\mathrm{cm}))$ according to Seikel, et al. [1].

\section{Material and Methods}

\section{Sample}

The data used in this study were obtained through the database of Team 5 Physical Education Institute Laboratory OPAPS for the academic year 2014-2015 [17]. In terms of player-related data, 163 male soccer players under 17 years, from the Algerian championship national territory was examined in parameters (anthropometric and physiological decide for the current study) by Team 5 at the end of the physical preparation for the year 2014-2015 after the agreement with their coach, were All examinations were realized for the first weeks before the start of championship. Whereas to expert the study protocol and methods, we choose the laboratory OPAPS "Institute of Physical Education of our University" who approve it by the professors of football and psychologist.

\section{Testing protocol}

Vital capacity: Vital capacity was calculating based on formula $($ vital capacity $(\mathrm{ml})=(27.63-0.112 \times$ age $) \times$ height $(\mathrm{cm}))$ according to Seikel et al. [1], where The normal vital capacity varies between 3.5 and 6 litres while set that vital capacity increases in response to physical training, to provide an increased and more efficient supply of Oxygen to working muscles $[18,19]$.

The maximal aerobic capacity: We have chosen the maximal aerobic capacity based on the formula Test Cooper [16] $\left(\mathrm{VO}_{2} \max =22.351\right.$ $\mathrm{d}(\mathrm{km})-11.288(\mathrm{ml} / \mathrm{min} / \mathrm{kg}))$ where that the Cooper 12 -minute test, the 1.5-mile test, the Rockport One-Mile Fitness Walking Test and the multi-stage shuttle have A corresponding $\mathrm{VO}_{2}$ max obtained by the formula where set them accurate which is correlated between 9095\% wherevers indict that the Cooper test provide a better picture

*Corresponding author: Zerf Mohammed, Physical Education Institute Laboratory OPAPS, University of Mostaganem, Mostaganem, Algeria, Tel: +213773450124 E-mail: biomeca.zerf@outlook.com

Received April 23, 2016; Accepted June 10, 2016; Published June 14, 2016

Citation: Mohammed Z, Abelatif H, Mokhtar M, Ali B (2016) Height versus Weight which Cassel Parameter Determine Pulmonary Functions Fitness among the Algerians Soccer Players. J Pulm Respir Med 6: 353. doi:10.4172/2161 105X.1000353

Copyright: ( 2016 Mohammed Z, et al. This is an open-access article distributed under the terms of the Creative Commons Attribution License, which permits unrestricted use, distribution, and reproduction in any medium, provided the original author and source are credited. 
Citation: Mohammed Z, Abelatif H, Mokhtar M, Ali B (2016) Height versus Weight which Cassel Parameter Determine Pulmonary Functions Fitness among the Algerians Soccer Players. J Pulm Respir Med 6: 353. doi:10.4172/2161-105X.1000353

Page 2 of 3

of endurance of maximal aerobic capacity. However, confirm that maximal aerobic capacity is rarely the limiting factor in performing daily work tasks where the Progressive respiratory muscular weakness leads to restrictive lung disease [20-24].

Weight and height: Height $(\mathrm{m})$ and weight $(\mathrm{kg})$ were each measured in the standing position where confirm that the $\mathrm{VO}_{2}$ peak is associated with biological status after controlling for height and weight $[25,26]$.

\section{Statistical analyses}

Data analysis was performed using SPSS 22.0 for Windows (32bit). Data obtained from the tests showed a normal distribution and were presented as mean \pm standard deviation and Shapiro-Wilk test. A Regression analyses were conducted to analyse the combined of the variables chosen to study where the relationship between the variables was analysed by Pearson correlations ( $r$ ).

\section{Results}

The characteristics of the study sample are presented in Table1. However, most traits differed by the variables consist in BMI which reject Normality based on Shapiro-Wilk test. The Mean \pm SD of all the variables shows Good level of fitness and physiological characteristics of the participants.

All the correlations in the Table 2 are significant at $\mathrm{p} \leq 0.05$, in the opposite of weight and BMI.

Through the Table 3 model method Stepwise showed a strong and significant positive association between Vital capacity and $\mathrm{VO}_{2}$ max.

Through the Table 4 mode1 method Stepwise showed a strong and significant positive association between $\mathrm{VO}_{2}$ max and Height whereas the program Excluded Weigh from the regression.

Through the Table 5 model method Stepwise showed a strong and significant positive association between Vital capacity and Height whereas the program Excluded Weigh from the regression.

\begin{tabular}{|c|c|c|c|}
\hline \multicolumn{4}{|c|}{ Physiological characteristics } \\
\hline Variable & Vital capacity & \multicolumn{2}{|c|}{$\mathrm{VO}_{2} \max$} \\
\hline Sample size & \multicolumn{3}{|c|}{163} \\
\hline Mean \pm SD & $4434.56 \pm 190.22$ & \multicolumn{2}{|c|}{$44.83 \pm 1.64$} \\
\hline Mini \pm Maxi value & $3995.78 \leq 4917.89$ & \multicolumn{2}{|c|}{$39.96 \leq 49.39$} \\
\hline Coefficient of Skewness & $\begin{array}{c}0.16 \\
(P=0.40)\end{array}$ & \multicolumn{2}{|c|}{$\begin{array}{c}0.13 \\
(P=0.49)\end{array}$} \\
\hline Coefficient of Kurtosis & $\begin{array}{c}-0.1664 \\
(P=0.73)\end{array}$ & \multicolumn{2}{|c|}{$\begin{array}{c}0.45 \\
(P=0.22)\end{array}$} \\
\hline $\begin{array}{l}\text { Shapiro-Wilk test } \\
\text { for Normal distribution }\end{array}$ & $\begin{array}{c}\mathrm{W}=0.9923 \\
\text { accept } \\
\text { Normality } \\
(\mathrm{P}=0.53)\end{array}$ & \multicolumn{2}{|c|}{$\begin{array}{c}\mathrm{W}=0.99 \\
\text { accept } \\
\text { Normality } \\
(\mathrm{P}=0.44)\end{array}$} \\
\hline \multicolumn{4}{|c|}{ Anthropometric characteristics } \\
\hline Variable & Weight & Height & BMI \\
\hline Mean \pm SD & $64.28 \pm 7.60$ & $174.51 \pm 6.36$ & $\begin{array}{c}21.14 \pm \\
1.75\end{array}$ \\
\hline Mini $\leq$ Maxi value & $48.60 \leq 78$ & $156 \leq 186$ & $\begin{array}{c}18.01 \leq \\
25.86\end{array}$ \\
\hline Coefficient of Skewness & $\begin{array}{c}0.23 \\
(P=0.20)\end{array}$ & $\begin{array}{c}0.14 \\
(P=0.44)\end{array}$ & $\begin{array}{c}0.61 \\
(P=0.002)\end{array}$ \\
\hline Coefficient of Kurtosis & $\begin{array}{c}0.7319 \\
(P=0.08)\end{array}$ & $\begin{array}{c}0.49 \\
(P=0.19)\end{array}$ & $\begin{array}{c}-0.12 \\
(P=0.82)\end{array}$ \\
\hline $\begin{array}{l}\text { Shapiro-Wilk test } \\
\text { for Normal distribution }\end{array}$ & $\begin{array}{c}W=0.98 \\
\text { accept } \\
\text { Normality } \\
(P=0.09)\end{array}$ & $\begin{array}{c}\mathrm{W}=0.98 \\
\text { accept } \\
\text { Normality } \\
(\mathrm{P}=0.28)\end{array}$ & $\begin{array}{c}W=0.96 \\
\text { reject } \\
\text { Normality } \\
(P=0.0002)\end{array}$ \\
\hline
\end{tabular}

Table 1: Presents the Baseline characteristics of the participants Physiological and Anthropometric characteristics by total group.

\begin{tabular}{|c|c|c|c|c|c|c|}
\hline \multicolumn{2}{|c|}{ Correlations। } & Weight & BMI & Height & $\mathrm{VO}_{2}$ & Vital \\
\hline \multirow{2}{*}{ Weight } & $\begin{array}{l}\text { Pearson } \\
\text { Correlation }\end{array}$ & \multirow[t]{2}{*}{1} & 0.12 & $0.66^{\star *}$ & $0.64^{* *}$ & $0.40^{\star *}$ \\
\hline & Sig. (2-tailed) & & 0.13 & 0.00 & 0.00 & 0.00 \\
\hline \multirow{2}{*}{ BMI } & $\begin{array}{l}\text { Pearson } \\
\text { Correlation }\end{array}$ & 0.12 & \multirow[t]{2}{*}{1} & $-0.49^{* *}$ & $-0.48^{* *}$ & $-0.26^{* *}$ \\
\hline & Sig. (2-tailed) & 0.13 & & 0.00 & 0.00 & 0.00 \\
\hline \multirow[t]{2}{*}{ Height } & $\begin{array}{l}\text { Pearson } \\
\text { Correlation }\end{array}$ & $0.66^{\star *}$ & $-0.49^{* *}$ & \multirow[t]{2}{*}{1} & $0.97^{\star *}$ & $0.58^{* *}$ \\
\hline & Sig. (2-tailed) & 0.00 & 0.000 & & 0.00 & 0.00 \\
\hline \multirow{2}{*}{$\mathrm{Vo}_{2} \mathrm{MAX}$} & $\begin{array}{l}\text { Pearson } \\
\text { Correlation }\end{array}$ & $0.64^{* *}$ & $-0.48^{* *}$ & $0.97^{* *}$ & \multirow{2}{*}{1} & $0.57^{* *}$ \\
\hline & Sig. (2-tailed) & 0.00 & 0.00 & 0.00 & & 0000 \\
\hline \multirow{2}{*}{$\begin{array}{c}\text { Vital } \\
\text { capacity }\end{array}$} & $\begin{array}{l}\text { Pearson } \\
\text { Correlation }\end{array}$ & $0.40^{* *}$ & $-0.26^{* *}$ & $0.58^{* *}$ & $0.57^{\star *}$ & \multirow[t]{2}{*}{1} \\
\hline & Sig. (2-tailed) & 0.00 & 0.00 & 0.00 & 0.00 & \\
\hline \multicolumn{7}{|c|}{${ }^{* *}$. Correlation is significant at the 0.01 level (2-tailed). } \\
\hline
\end{tabular}

Table 2: Presents the correlations between the variables tested in the current study.

\begin{tabular}{|l|l|l|l|l|l|l|l|l|}
\hline $\begin{array}{l}\text { Model } \\
\text { Stepwise }\end{array}$ & $\mathbf{R}$ & $\mathbf{R}^{\mathbf{2}}$ & $\begin{array}{l}\text { Adjusted } \\
\mathbf{R}^{\mathbf{2}}\end{array}$ & Coefficients $^{\mathbf{a}}$ & $\mathbf{T}$ & $\mathbf{P}$ & $\mathbf{f}$ & $\mathbf{P}$ \\
\hline 1 & $0.57^{\mathrm{a}}$ & 0.32 & 0.31 & (Constant) & 8.72 & 0.00 & 76.04 & 0.00 \\
\hline
\end{tabular}

Variables Entered: $V O$ max

Dependent Variable: Vital capacity / Predictors: (Constant), $\mathrm{VO}_{2}$ max

Table 3: Presents the Results of regression analyses relating Vital capacity and $\mathrm{VO}_{2}$ max.

\begin{tabular}{|l|l|l|l|l|l|l|l|l|}
\hline $\begin{array}{l}\text { Model } \\
\text { Stepwise }\end{array}$ & $\mathbf{R}$ & $\mathbf{R}^{\mathbf{2}}$ & $\begin{array}{l}\text { Adjusted } \\
\mathbf{R}^{\mathbf{2}}\end{array}$ & Coefficients $^{\mathbf{a}}$ & $\mathbf{T}$ & $\mathbf{P}$ & $\mathbf{f}$ & $\mathbf{P}$ \\
\hline 1 & $0.97^{\mathrm{a}}$ & 0.94 & 0.94 & (Constant) & 1.29 & 1.29 & 2681.18 & 0.00 \\
\hline
\end{tabular}

Variables Entered: Height, Weight.

Dependent Variable: $\mathrm{VO}_{2}$ max/Predictors: (Constant), Height Excluded Variables: Weight.

Table 4: Presents the Results of regression analyses relating $\mathrm{VO}_{2}$ max and Height $\&$ Weight.

\begin{tabular}{|l|l|l|l|l|l|l|l|l|}
\hline $\begin{array}{l}\text { Model } \\
\text { Stepwise }\end{array}$ & $\mathbf{R}$ & $\mathbf{R}^{\mathbf{2}}$ & $\begin{array}{l}\text { Adjusted } \\
\mathbf{R}^{\mathbf{2}}\end{array}$ & Coefficients $^{\mathbf{a}}$ & $\mathbf{T}$ & $\mathbf{P}$ & $\mathbf{f}$ & $\mathbf{P}$ \\
\hline 1 & $0.58^{\mathrm{a}}$ & 0.34 & 0.33 & (Constant) & 4.23 & 0.00 & 81.56 & 0.00 \\
\hline
\end{tabular}

Variables Entered: Height, Weight

Dependent Variable: Vital capacity / Predictors: (Constant), Height Excluded Variables: weight.

Table 5: Presents the Results of I regression analyses relating Vital capacity categories and Height \& Weight.

\section{Discussion}

Based on the statistical applied. Our results confirm:

- There is a strong positive relationship between maximal aerobic capacity and the Vital capacity. Where our result line with Collins et al. [27] that a positive relationship exists between ventilatory capacity and aerobic capacity which has been mentioned in several studies. Whereas Grant et al. [28] confirm that the meaning is within the pulmonary functioning and its report with the aerobic fitness where Grupe et al. [29] confirm that the vital capacity is a limiting factor of aerobic capacity [30].

- Height is the most predictor of Vital capacity. Where our results are correlate with the judgement of Ghai [15] that the relation to body weight, for an average healthy person, the prediction formula is Vital capacity. Whereas Hess et al. [31] confirm to 
Citation: Mohammed Z, Abelatif H, Mokhtar M, Ali B (2016) Height versus Weight which Cassel Parameter Determine Pulmonary Functions Fitness among the Algerians Soccer Players. J Pulm Respir Med 6: 353. doi:10.4172/2161-105X.1000353

predict pulmonary function equations using weight should not be used because obese patients will have their pulmonary function overestimated and gain. From the proof, our results of BMI $(18.01 \leq 25.86)$ are correlate with OMS recommendations: (BMI $<25$ ) equal normal body weight, over $\geq 25$ equal overweight [32] where these results explain the strong negative relation between the BMI and the other variables, except in BMI and Weight which is not significant. Based on the above we agree that the body mass index (BMI) is considered to be one of the most objective anthropometric indices, when its permits the correction of body weight for height [33].

- Height is the most predictor of the maximal aerobic capacity in our case, where our results line with the notice that you may want to adjust your aerobic capacity score (in litres) to account for body size because big people use more litres of Oxygen simply [34].

\section{Conclusion}

Our study evaluated relationships between two surrogate measured, cardiorespiratory fitness versus the Pulmonary Functions as Parameters to determine the Physiological profile among soccer players.

Where our background confirms that weight-for-height as a relationship, were not considered in the analysis among soccer players according to Thomas Reilly in the similar studies. Our finds confirmed to maintain a good aerobic fitness, the player must have enhanced pulmonary function and an improved capacity for Oxygen $[35,36]$. Moreover, the analysis of body composition is important for any complete fitness program, whether it is important for our players and coaches to identify the changes in body composition during growth to allow for the accurate interpretation of impact of program training. To conclude we agree that Athletes' must estimate them ideal weights based on age, height and lowest in weight as the crucial physiological characteristic and low percentage body fat as the most important physical characteristic [37-39].

From the proof the current study supports the hypothesis that the relationship weight-for-height is the best way to maintain a good aerobic fitness and ideal weights, view the limitations of this study we agree that, further studies are needed to implement the actual findings associated with this hypothesis [40].

\section{References}

1. Seikel AJ, Drumright DG, King DW (2015) Anatomy \& Physiology for Speech Language, and Hearing. CengageBrain.com, USA, p: 155.

2. Clemente FM, Couceiro MS, Martins FM, Ivanova MO, Mendes R (2013) Activity profiles of soccer players during the 2010 world cup. J Hum Kinet 30: 201-211.

3. Chin MK, Lo YS, Li CT, So CH (1992) Physiological profiles of Hong Kong élite soccer players. Br J Sports Med 26: 262-266.

4. Barros RM, Misuta MS, Menezes RP, Figueroa PJ, Moura FA, et al. (2007) Analysis of the distances covered by first division brazilian soccer players obtained with an automatic tracking method. J Sports Sci Med 6: 233-242.

5. Reilly T, Gilbourne D (2003) Science and football: a review of applied research in the football codes. J Sports Sci 21: 693-705.

6. Gregory G, Travis N (2015) Essentials of strength training and conditioning. (4th edn.), Human Kinetics, USA, p: 261.

7. Akbarnia BA, Yazici M, George $T$ (2015) The growing spine: management of spinal disorders in young children. Springer Shop, UK, p: 87.

8. Kumar BU (2016) Handbook of mechanical ventilation. New Delhi: The health Sciences Publisher, India, p: 23.

9. William E Prentice (2015) Get Fit, Stay Fit. F.A. Davis, USA, p: 77

10. Yabe K, Kusano K, Nakata H (2012) Adapted physical activity: health and fitness. Springer Shop, UK, p: 202.

11. Sujith S (2016) Physical effects of different intensive circuit training on selected motor. Lulu.com, USA, p: 28.

12. Dutton M (2012) Dutton's Orthopaedic Examination Evaluation and Intervention, ( $3^{\text {rd }}$ edn), McGraw Hill Professional, USA, p: 459.

13. Eston R, Eston RG, Reilly T (2009) Kinanthropometry and Exercise Physiology Laboratory Manual: Exercise physiology. Taylor \& Francis, USA, p: 175.

14. Orlando G (2013) Regenerative Medicine Applications in Organ Transplantation. Elsevier, UK, p: 673.

15. Hoeger W, Hoeger S (2009) Principles and Labs for Fitness and Wellness, CengageBrain.com, USA, p: 202.

16. The Cooper Institute, Welk G, Meredith MD (2009) Fitnessgram and Activitygram Test Administration Manual-Updated. ( $4^{\text {th }}$ edn), Human Kinetics, USA, p: 27.

17. http://www.univ-mosta.dz/index.php/k2/k2-user-page

18. Ghai CL (2012) A Textbook of Practical Physiology. New Delhi: Jaypee Brothers Medical Publishers, India, p: 155

19. Barker R (2003) BTEC National Sport Student Book. Heinemann, USA, p: 225

20. Ferré J, Leroux P (2009) Preparedness sports teacher qualifications. Editions Amphora, France, p: 436.

21. Gormley J, Hussey J (2009) Exercise Therapy: Prevention and Treatment of Disease. Wiley.com, USA, p: 83.

22. Pinchas $Y$ (2006) The Complete Holistic Guide to Working Out in the Gym University of Calgary Press, Canada, p: 23.

23. Saari O, Hintsa A (2016) The Core: Better Life, Better Performance. Filand.

24. DeLisa JA, Gans BM, Walsh NE, (2005) Physical Medicine and Rehabilitation: Principles and Practice. Wolters Kluwer Health, USA, p: 924.

25. Goto Y, Yokokawa H, Fukuda H, Naito T, Hisaoka T, et al. (2015) Body mass index and waist circumference are independent risk factors for low vital capacity among Japanese participants of a health checkup: a single-institution crosssectional study. Environ Health Prev Med 20: 108-115.

26. Hebestreit H, Bar-ORO, (2008) The Young Athlete. Blackwell Publishing Ltd, USA, p: 453.

27. Collins KJ, Roberts DF, (2009) Capacity for Work in the Tropics. Cambridge University Press, UK, p: 34

28. Grant I, Adams K (2009) Neuropsychological Assessment of Neuropsychiatric and Neuromedical Disorders. Oxford University Press, UK, p: 338.

29. Grupe O, Kurz D, Teipel JM (2012) Sport in the Modern World Chances and Problems. Springer Shop, UK, p: 503.

30. Narvani A, Thomas P, Lynn B (2014) Key Clinical Topics in Sports and Exercise Medicine. JP Medical Ltd, UK, p: 106.

31. Hess DR, MacIntyre NR, Galvin WF, (2015) Respiratory Care: Principles and Practice. Jones \& Bartlett Learning, USA, p: 147.

32. Federici A, Daniela Testa D (2010) Physical activity in Italian prisons. The role of physical educator. Armando Editore, Italy, p: 149.

33. Allen L, Prentice A (2005) Encyclopedia of Human Nutrition. Elsevier, USA, p: 450

34. Chuck B, Masurier L (2014) Guy, Fitness for Life. (6 $6^{\text {th }}$ edn), Human Kinetics USA, p: 160

35. Reilly T, Williams MA (2003) Science and Soccer. Routledge, USA, p: 302.

36. Renström PAFH (2008) Handbook of Sports Medicine and Science, Tennis. Wiley.com, USA, p: 51

37. McMurray RG (1998) Concepts in Fitness Programming. CRC Press, USA, p: 63.

38. Draper N, Marshall H (2014) Exercise Physiology: For Health and Sports Performance. Routledge, USA, p: 194

39. Reilly T, Secher N, Snell P (2005) Physiology of Sports. Routledge, USA, p: 399.

40. Scicchitanoa P, Camelib M, Maielloc M, Modestid PA, Muiesane ML, et al. (2014) Nutraceuticals and dyslipidaemia: Beyond the common therapeutics. $J$ Funct Foods 6: 11-32. 